\title{
Ambientes de ensino e aprendizagem de Cálculo Diferencial e Integral organizados a partir de episódios de resolução de tarefas: uma proposta
}

\section{RESUMO}

André Luis Trevisan andrelt@utfpr.edu.br 0000-0001-8732-1912

Universidade Tecnológica Federal do Paraná, Londrina, Paraná, Brasil

Marcele Tavares Mendes marceletavares@utfpr.edu.br 0000-0001-6844-6525

Universidade Tecnológica Federal do Paraná, Londrina, Paraná, Brasil
Em geral, disciplinas de Cálculo Diferencial e Integral (CDI) são conduzidas por meio do roteiro: apresentações de definições, exemplos e ilustrações de conceitos presentes na ementa da disciplina, resolução de exercícios-tipo e realização de prova escrita. Em contrapartida, embasados em pesquisas na área de ensino de CDI e na Educação Matemática Realística, (RME) defendemos a organização de ambientes de ensino e aprendizagem pautados em episódios de resolução de tarefas. O objetivo deste trabalho é apresentar uma caracterização desse ambiente, construída à luz dos pressupostos da RME e da pesquisa e reflexão sobre nossa prática. Nessa caracterização, destacam-se o contexto real de trabalho, o perfil dos estudantes, a organização dos conteúdos e as tarefas que compõem o ambiente. Este texto é resultado de uma pesquisa qualitativa, que apresenta análises baseadas tanto em estudos de fundo teórico quanto em dados já coletados nas turmas nas quais a proposta tem sido implementada.

PALAVRAS-CHAVE: Ensino de Matemática. Ensino de Cálculo Diferencial e Integral. Ambiente de ensino e aprendizagem. Episódios de resolução de tarefas. 


\section{INTRODUÇÃO}

A Educação Matemática (EM) no Ensino Superior tem sido foco de pesquisa há algumas décadas. A importância do tema é evidenciada ao identificarmos nos principais eventos da área, tanto em âmbito nacional (como o SIPEM - Seminário Internacional de Pesquisa em Educação Matemática e o ENEM - Encontro Nacional de Educação Matemática) quanto internacional (a exemplo do PME - Psychology of Mathematics Education e ICME - International Congress on Mathematics Education), grupos de discussão com esse foco específico.

Rasmussen, Marrongelle e Borba (2014) lembram que avanços em fundamentos teóricos a respeito do ensino e da aprendizagem da Matemática vêm desempenhando uma forte influência nas pesquisas no Ensino Superior. Pesquisas desenvolvidas no âmbito da EM apontam que abordagens de ensino de Matemática promissoras são aquelas em que os alunos trabalham de forma colaborativa, com tarefas que envolvam a resolução de problemas integrando recursos tecnológicos a fim de propiciar a reflexão, promover a interação interativa/dialógica e que tenham potencial para facilitar a aprendizagem dos estudantes.

No entanto, implementar tais abordagens em salas de aula regulares continua a ser um problema em EM (LITHNER, 2008). Mesmo depois de algumas décadas de pesquisa nessa direção, o que se observa é uma discrepância entre ideias geralmente aceitas e compartilhadas pela comunidade de pesquisadores e a realidade na maioria das salas de aula. Segundo Stingler e Hiebert (2004, p. 12), a maioria das propostas de reformas no ensino da Matemática "pararam na porta da sala de aula", e ela mudou "muito pouco nos últimos 100 anos".

Consideramos as ideias de Freudenthal $(1971,1991)$ e os pressupostos da abordagem de ensino Educação Matemática Realística (RME) pertinentes para o desenvolvimento da proposta aqui apresentada e para promover um repensar a respeito do ambiente em que se dão os processos de ensino e de aprendizagem de CDI. Freudenthal propõe que a matemática seja pensada como uma atividade humana, e que seja dada aos estudantes a oportunidade de desenvolvê-la, por meio de um processo de reinvenção guiada, respaldada em processos que tomam como ponto de partida diferentes situações que possam ser matematizadas. Ancoramo-nos na RME por se tratar de uma abordagem utilizada no desenvolvimento, aperfeiçoamento e estudo de materiais instrucionais em EM.

Este texto é resultado de um projeto de pesquisa intitulado "Investigação de um ambiente educacional para o Cálculo Diferencial e Integral (CDI) em condições reais de ensino", submetido e aprovado no Edital Universal 14/2014 do CNPq. O objetivo geral do projeto é investigar os processos envolvidos na caracterização, na implementação e na avaliação de um ambiente de ensino e aprendizagem para a disciplina de CDI, considerando as condições reais às quais estamos sujeitos.

Entendemos que uma proposta factível deva ser pensada levando em conta, por um lado, aspectos apontados pelas pesquisas realizadas no campo da EM (portanto, sejam referenciadas teoricamente) e que difiram significativamente de aulas centradas no livro didático, mas, por outro, atendam demandas rotineiras da sala de aula e estejam alinhadas com a organização didático-pedagógica proposta pela instituição (comprometidas com um currículo obrigatório, com o projeto político-pedagógico do curso, com a atribuição de uma nota ao fim de um período). 
Ambiente de ensino e aprendizagem é um conceito ainda em elaboração no âmbito do desenvolvimento do projeto, mas nosso entendimento, conforme apontado por Borssoi, Silva e Ferruzzi (2016, p.4), é que essa caracterização deve levar "em consideração aspectos estruturais (estrutura da instituição de ensino, a natureza dos cursos de graduação oferecidos por ela, o perfil do egresso que se almeja e o perfil dos alunos matriculados na disciplina de Cálculo, entre outros) e aspectos pedagógicos e procedimentais".

De acordo com Moreira (2007, sp),

[...]um ambiente de aprendizagem escolar é um lugar previamente organizado para promover oportunidades de aprendizagem e que se constitui de forma única na medida em que é socialmente construído por alunos e professores a partir das interações que estabelecem entre si e com as demais fontes materiais e simbólicas do ambiente.

Defendemos que tais ambientes sejam pautados em episódios de resolução de tarefas (adaptação da expressão shift problem lessons, proposta por Palha (2013), respaldada nos pressupostos da RME), nos quais os estudantes tenham um papel ativo trabalhando, quando possível, em grupos e em tarefas não precedidas de exemplos, que sejam desencadeadoras de discussões e que contribuam para elaborações conceituais. O papel do professor, ao invés de sempre fornecer explicações, é incentivar os estudantes a apresentarem e discutirem suas ideias durante as realizações das tarefas propostas, bem como conduzir a sistematização dos conceitos a elas subjacentes. Assim, antes de introduzir um conceito mediante sua definição formal, o estudante é convidado a explorá-lo intuitivamente, levando em conta suas concepções e imagens conceituais prévias.

O objetivo deste trabalho é apresentar uma caracterização desse ambiente de ensino e aprendizagem para turmas de CDI nos cursos de graduação da instituição de origem dos autores, com destaque aos seguintes aspectos: o contexto real de trabalho, o perfil dos estudantes, a organização dos conteúdos e as tarefas que compõem o ambiente. A intenção subjacente é provocar, por meio dessa caracterização, um repensar a respeito desse ambiente em que se dão os processos de ensino e de aprendizagem de CDI.

\section{PROCEDIMENTOS METODOLÓGICOS}

Os autores deste texto são jovens pesquisadores da EM, professores de disciplinas matemáticas do Ensino Superior; além de responsáveis por turmas de CDI na condição de regentes, orientam trabalhos de iniciação científica, de conclusão de curso, monografias de especialização e dissertações, sendo seus orientandos coparticipantes das ações desenvolvidas em sala, e também pesquisadores dos dados que aí se originam.

Este artigo intenta apresentar uma caracterização do que temos denominado ambientes de ensino e aprendizagem para aulas de CDI, pautados em episódios de resolução de tarefas. Tal caracterização baseia-se tanto nos estudos da fundamentação teórica do projeto quanto em dados já coletados nas turmas nas quais a proposta foi implementada.

Como primeira etapa do projeto, o grupo inicialmente realizou um refinamento bibliográfico, buscando nos aproximar da temática da pesquisa 
(ensino e aprendizagem de CDI) juntamente com estudos teóricos que objetivaram subsidiar o desenvolvimento da investigação e a análise das ações desenvolvidas com os estudantes. A fase relacionada aos estudos da fundamentação teórica se deu em paralelo com as demais fases da investigação (desenho, aplicação, redesenho e análise de tarefas), uma vez que os estudos teóricos permearam toda a pesquisa, ocorrendo sempre que necessária uma revisitação dos mesmos.

A metodologia que respalda esse processo de elaboração de tarefas é o Design Research (Pesquisa de desenvolvimento), que tem como principal objetivo o desenvolvimento de materiais projetados para dar suporte aos processos de ensino e de aprendizagem (GRAVEMEIJER; COBB, 2006). O entrelaçamento da prática e da teoria é uma característica essencial dessa abordagem, assim como a seu caráter cíclico: design, experiência de ensino e análise retrospectiva, sendo esta última o fomento para um novo ciclo que começa com o design.

Para a coleta de dados, foram utilizados instrumentos como diários de campo, gravações em áudio e vídeo, questionários e produção escrita dos estudantes em tarefas propostas nas diferentes turmas, ao longo de cada semestre dos anos de 2016 e 2017. O envolvimento dos alunos com as tarefas é o objeto de análise, e a análise dos dados coletados, embora subsidiada pelos referenciais teóricos que fundamentam a pesquisa, vem cercada de compreensão e entendimento dos pesquisadores.

\section{RESULTADOS E DISCUSSÃO}

Objetivando apresentar tal caracterização, elegemos como elementos: (i) o contexto real de trabalho, (ii) o perfil dos estudantes, (iii) a organização dos conteúdos e (iv) as tarefas que compõem o ambiente.

\section{O CONTEXTO REAL DE TRABALHO}

As turmas nas quais temos implementado nossa proposta de trabalho são compostas por estudantes que ingressam nos cursos de graduação da instituição, na qual os autores atuam como docentes permanentes. Incluem os cursos diurnos de (1) Engenharia Ambiental, (2) Engenharia de Materiais, (3) Engenharia Mecânica e (4) Engenharia Química e os cursos noturnos de (5) Tecnologia em Alimentos, (6) Licenciatura em Química e (7) Engenharia de Produção. Desde o início do projeto, no primeiro semestre de 2015, foram coletados dados em turmas dos cursos (2), (5), (6) e (7), além de turmas formadas por estudantes de todos os cursos que não obtiveram aprovação anterior na disciplina, que cursam a disciplina de CDI na modalidade semipresencial. Essas turmas iniciam com 44 alunos de ingresso regular a cada semestre, além de 6 a 8 estudantes da modalidade especial.

A seleção de candidatos para as vagas aos cursos de graduação é realizada pelo Sistema de Seleção Unificado (SISU/MEC). Enquanto houver vagas, são realizadas chamadas adicionais, fazendo com que alunos ingressem na turma até três semanas após o início das aulas. A cada semestre, são abertos editais para possíveis trocas de cursos, e os alunos podem optar pela transferência para um curso de graduação do mesmo eixo tecnológico. Simultaneamente são destinadas vagas para transferências externas, para alunos de outras instituições que almejarem uma vaga em um curso de graduação da instituição. 
Como detalhado em Ramos, Fonseca e Trevisan (2016), destacamos que muitos desses estudantes iniciam um curso que não foi sua primeira opção no Sisu. Isso pode levá-lo a abandonar o curso nas primeiras semanas, abrindo vagas adicionais e novas listas de chamada. Tais fatos geram certa "instabilidade" nas primeiras semanas de aula do curso, e um número significativo de desistências ao longo dele.

Os alunos das engenharias e da licenciatura cursam, além do CDI-1 (90h/aula - seis aulas semanais), as disciplinas de CDI-2 (60h/aula - 4 aulas semanais) e Equações Diferenciais (60h/aula - 4 aulas semanais). Os cursos (2), (3) e (4) acima nomeados cursam também CDI-3 e Cálculo Numérico (60h/aula - 4 aulas semanais). O curso de Tecnologia tem em sua grade uma única disciplina de CDI com 60h/aula -4 aulas semanais.

Em termos de infraestrutura, destacamos que as salas de aula seguem a disposição "usual" (quadro negro à frente, mesa do professor e carteiras enfileiradas), além de data show.

Os estudantes têm à disposição atividades de monitoria, sob responsabilidade de estudante veterano escolhido por processo seletivo no início de cada semestre letivo. Além disso, o professor destina $25 \%$ da sua carga horária em sala de aula, em horários nos quais está disponível, para atendimento extraclasse. Dados organizados pelo Departamento de Educação da Universidade do campus (em caráter informal) indicam, no geral, uma utilização muito baixa desses recursos (monitoria e atendimento de professor) por parte dos alunos. Embora não seja objetivo discutir essa questão aqui, nossa hipótese é que "essas atividades acabam se caracterizando como espaços de reprodução das práticas tradicionais de sala de aula e, portanto, alinhá-las com uma proposta de ambiente de aprendizagem pautados em resolução de tarefas é uma questão em aberto" (RAMOS; FONSECA; TREVISAN, 2016, p. 6), demandando investigações.

\section{O PERFIL DOS ESTUDANTES}

Identificamos nos estudantes que ingressam em nossas turmas de CDI características similares às apontadas pela literatura. Para Alvarenga e Sampaio (2016),

[...] nosso estudante do ensino superior chega às salas de aula com uma visão projetada da maneira como foi aprendida via seus professores e livros didáticos, logo chega com uma visão compartimentada e restrita, mas se depara com, por exemplo, na disciplina de Cálculo Diferencial e Integral a necessidade de mobilizar conhecimentos integrados, inter-relacionados e na busca de compreender e analisar fenômenos os quais aí são tratados, ele se vê numa situação de inércia (ALVARENGA, SAMPAIO, 2016, p.132).

Quando inicia a disciplina de CDI no Ensino Superior, nosso estudante geralmente apresenta características oriundas de sua rotina de estudos na Educação Básica, tais como: falta de experiências anteriores com tarefas de caráter investigativo; expectativa de aulas expositivas, sucedidas pela resolução de tarefas similares aos exemplos apresentados pelo professor; concepções equivocadas acerca de alguns conceitos matemáticos (muitas vezes decorridas do foco na mecanização de processos, em vez de compreensão e atribuição de significado); 
hábito de trabalhar, na maioria das vezes, de forma individual, tendo dificuldade em expor e discutir suas ideias em grupo ou para toda a sala.

Os altos índices de reprovação, o baixo rendimento acadêmico e as dificuldades enfrentadas pelos alunos que ingressam no Ensino Superior são objetos de investigação por professores e pesquisadores da EM há algumas décadas. Com respeito às dificuldades enfrentadas pelos estudantes na disciplina de CDI, Artigue (1995) aponta que provêm (i) da complexidade dos objetos matemáticos do Cálculo; (ii) da construção e formalização do conceito de limite como núcleo do conteúdo de Cálculo, e o tratamento dado no seu ensino; (iii) da ruptura álgebra/cálculo, uma consequente "brecha" entre o pensamento analítico e o algébrico.

Nessa mesma direção, Rezende (2003) ressalta que essas dificuldades não podem ser tratadas apenas como algo inerente ao estudante, mas também ao ambiente de ensino e aprendizagem e ao próprio objeto matemático. Com vistas a minimizar algumas delas, o autor sugere que, em vez de "construir os conhecimentos e conceitos do Cálculo num nível do conhecimento já sistematizado, deve-se ter em mente a construção de redes de significações das ideias básicas para, num momento posterior, buscar a sistematização dos elementos dessa rede" (REZENDE, 2003, p. 19). Trata-se, na abordagem defendida por Reis (2009, p.89), de considerar, na organização de um ambiente de ensino e aprendizagem para a disciplina de CDI, que a intuição deve, obrigatoriamente, estar presente nos processos de ensino e de aprendizagem e que "uma validação lógico-formal, isto é, rigorosa, jamais poderia prescindir da fase intuitiva e criativa das ideias matemáticas".

Para Borges e Moretti (2016, p.486), as pesquisas acerca das reprovações nas disciplinas matemáticas em serviço (como é nosso caso), desenvolvidas há algumas décadas, evidenciam que "o perfil do ingressante não corresponde àquele desejado pela universidade" e que "transformar o aluno em um acadêmico com hábitos eficientes de estudo, capacidade de expressão escrita e pré-requisitos para o Cálculo é entendida como uma desafiante tarefa dos professores de matemática dos primeiros anos de graduação". Ao investigar as relações com o saber estabelecidas por esses estudantes, os autores concluíram que relações do tipo objetivação-denominação (apropriação sem o entendimento de sentido, sem justificativas de regras e fórmulas) foram predominantes nas manifestações dos seus sujeitos de pesquisa, com sinais de aceitação simples e muito pouco de argumentação sobre a veracidade das proposições matemáticas, o que, para eles, acaba por gerar uma aprendizagem superficial e ajuda a explicar o baixo rendimento.

Andrade, Dias e Campos (2014, p.172) lembram que, no Brasil,

os cursos de exatas, em geral, introduzem uma disciplina de nivelamento no primeiro ano do Ensino Superior, mas quase sempre o que se faz é reproduzir o trabalho já realizado no Ensino Médio, sem uma articulação com disciplinas que irão utilizar os conhecimentos sobre função, que se supõe tenham sido trabalhados no Ensino Médio, o que não tem causado o impacto necessário.

Sobre essa questão, Vallejo, Martínez e Pluvinage (2012) apontam que, embora haja a necessidade de lidar com conceitos de pré-cálculo (como é o caso do conceito de função) para uma compreensão adequada do CDI, não há necessidade de ofertar aos estudantes cursos "remediais". Destacam que a 
experiência desenvolvida ao longo de um semestre de trabalho em uma turma regular de $\mathrm{CDI}$, por meio de uma metodologia de trabalho bastante próxima da que estamos propondo, possibilitou compreensão, por parte considerável dos estudantes, dos conceitos do $\mathrm{CDI}$, bem como avanços em relação às deficiências de pré-cálculo inicialmente apresentadas.

Para os autores, a transição do Ensino Médio para o Ensino Superior demanda uma mudança de formas de pensamento e novos modos de expressão, uma transição entre "idiomas" matemáticos (por eles denominados estratos). Os autores propõem a seguinte lista hierárquica de estratos a serem percorridos pelos estudantes: numérico (domínio dos números inteiros e racionais e uso correto das quatro operações), racional (domínio de razões e proporções), algébrico (uso adequado do sistema matemático de signos da álgebra) e funcional (uso de relações funcionais).

Uma avaliação diagnóstica aplicada por Vallejo, Martínez e Pluvinage (2012) a estudantes ingressantes em um curso de CDI revelou uma situação muito próxima da que vivenciamos: uma minoria dos estudantes está no estrato funcional, e muitos deles nem mesmo no estrato algébrico. Tal fato reforça a importância de tomarmos como pressuposto, na organização de um ambiente de ensino e aprendizagem, que os estudantes do ambiente real de ensino em geral não se encontram no estrato funcional (não podendo, portanto, assumi-lo como "prérequisito"), uma vez que isso será alcançado e consolidado no próprio trabalho na disciplina de CDI.

Do mesmo modo que Rasmussen, Marrongelle e Borba (2014), conhecemos bastante as dificuldades e os obstáculos enfrentados pelos estudantes na disciplina de CDI e o modo como aprendem conceitos particulares do CDI (como limites, derivadas e integrais); precisamos, portanto, nos engajar no desenvolvimento de pesquisas a partir de experiências desenvolvidas em ambientes reais de ensino e aprendizagem. A proposta de organizar e desenvolver pesquisas em ambientes de aprendizagem para a disciplina de CDI, que levem em conta as condições reais de ensino, como, por exemplo, esta proposta de ambientes pautados na resolução de tarefas, vai ao encontro dessas ideias.

\section{A ORGANIZAÇÃO DOS CONTEÚDOS}

Para Freudenthal $(1973,1991)$, precursor da RME, a matemática deve ser concebida como uma atividade que se pode aprender melhor "fazendo". Os estudantes, ao invés de serem meros receptores de uma matemática pronta, devem ser tratados como participantes ativos no processo educacional. A isso o autor denominou princípio da reinvenção. Em sua opinião, utilizar currículos cientificamente estruturados, em que os alunos são confrontados com uma matemática pronta, é uma inversão antididática. Nesse sentido, aponta que o CDI não seja tratado como um "amontoado de definições que estão acima de qualquer suspeita" (FREUDENTHAL, 1973, p. 512, tradução nossa), mas como uma ferramenta extremamente necessária à resolução de problemas.

Segundo Doorman e Maanen (2008, p. 10), não encontramos na história do desenvolvimento do CDI a sequência de conteúdos presente em livros, partindo do conceito de limites para os conceitos de derivada e integral, seguidos das técnicas de diferenciação e integração e, finalmente, o Teorema Fundamental do 
Cálculo. Essa inversão da história para a apresentação de um tópico matemático em um livro é um exemplo dessa inversão antididática, que tem suas origens em vista da elegância e da eficiência, porém, didaticamente falando, tem consequências consideráveis.

Para Freudenthal $(1973,1991)$, as aplicações devem ser utilizadas como ponto de partida que permite emergir e aprofundar conceitos fundamentais da matemática por meio de um progressivo processo de matematização (exploração da situação fazendo uso de ferramentas matemáticas). Assim, por exemplo, áreas e volumes podem ser calculados de forma intuitiva sem que definições mais gerais tenham sido apresentadas. 0 mesmo vale para densidades, velocidades e outros conceitos físicos subjacentes à história do CDI.

Vallejo e Pluvinage (2009), em uma análise dos programas curriculares tradicionais de CDI no México, destacam que, em sua maioria, apresentam o estudo dos números reais e das funções algébricas, seguido pelo estudo de limites como pré-requisito para o estudo de continuidade e derivação (bastante similar ao que o ocorre no Brasil e nos programas presentes nas ementas de CDI em nossa universidade, com a ressalva de que se inclui também o estudo da integração). Essa "ordem de aparição dos temas de Cálculo é contrária às necessidades que deram origem ao seu estudo e formalização" (VALLEJO; PLUVINAGE, 2009, p. 2), e acreditamos que acaba ocasionando uma perda da riqueza da exploração de problemas que deram origem ao $\mathrm{CDI}$, além do surgimento de obstáculos epistemológicos (como ocorre com o conceito de limite, por exemplo).

Baseados na análise do desenvolvimento histórico dos conteúdos, os autores sugerem duas diretrizes (linhas) para o ensino de CDI, nas quais temos baseado nossa proposta.

- Um primeiro curso de CDI não deve ser construído sobre o conhecimento prévio de estruturas formais dos números reais, nem em definições formais de função;

- Não é necessário construir os primeiros conceitos de CDI sobre a noção de limite, dado que, historicamente, o conceito de limite é posterior ao desenvolvimento de outros conceitos, como de derivadas e integrais (apoiando-se em explorações numéricas e em ideias da geometria presentes no estudo dos movimentos).

Cuevas e Mejía (2005) sugerem a organização de um curso de CDI que incorpore os elementos a seguir.

- Antes de introduzir um conceito matemático, deve-se partir de uma tarefa que envolva um contexto de interesse do estudante, buscando que ele realize alguma ação (não necessariamente física, mas, no caso, mental), para que, a partir da resolução elaborada, tal conceito possa ser sistematizado.

- Deve-se propor aos estudantes tarefas que envolvam operações tanto na ordem direta quanto inversa (por exemplo, propor situações que requeiram determinar intervalos de crescimento e decrescimento de uma função, assim como situações que requeiram construir uma função cujos intervalos de monotonia sejam conhecidos). 
- Visualizar e operar certo conceito em distintos sistemas de representação (no sentido proposto por Duval (2003 apud CUEVAS; MEJÍA, 2005)), bem como operações de conversão entre as diversas representações.

- Esse conceito deve fazer parte de um tema posterior de maior complexidade, como parte de uma estrutura necessária para que o estudante aborde uma nova tarefa.

Os autores ressaltam que esses elementos não podem estar presentes em tarefas que contemplem todos os conceitos imersos em um curso de CDI, sendo preciso destacar os conceitos mais importantes, o que se aproxima da proposta aqui apresentada de constituição de ambientes de ensino e aprendizagem pautados em episódios de resolução de tarefas. A determinação de contextos para a elaboração dessas tarefas pode ser feita ao resgatarmos o desenvolvimento histórico dos conceitos de Cálculo por meio de problemas de variações de grandezas (inclinação de uma reta - derivada) e a acumulação de quantidades (área debaixo de uma curva - integral).

Weigand (2014) apresenta ressalvas com relação às abordagens de ensino de CDI que abordam mais intuitivamente os conceitos envolvidos, como, por exemplo, limite ou derivada. Para ele, uma abordagem de caráter mais formal (baseada na definição de limite a partir do conceito de sequência) tem sido transformada ou substituída por outra, de caráter mais intuitivo.

Compreendemos que, se, por um lado, uma exploração restrita apenas a aspectos intuitivos, sem a preocupação com a definição formal, reforça interpretações simplistas ou mesmo errôneas trazidas por estudantes que ingressam num curso de CDI, por outro, uma abordagem mais formal pode levar os estudantes a "manipular símbolos" sem atribuir-lhes significados. Dito de outro modo, aparta-se(?) uma abordagem orientada apenas às aplicações de uma abordagem orientada apenas aos conceitos. Defendemos uma associação dos dois olhares, de tal modo que a sistematização de um conceito aconteça a partir da reflexão sobre sua utilização como uma ferramenta no lidar com as tarefas.

Weigand (2014) defende uma "revitalização" do conceito de sequência em um curso de CDI, não como um tópico específico, mas como um conteúdo distribuído ao longo do programa da disciplina, com base nos seguintes argumentos: (i) muitos problemas que envolvem aplicações reais podem ser modelados por meio de sequências, (ii) muitos problemas matemáticos podem ser resolvidos utilizando sequências como recurso e (iii) sequências (enquanto funções de domínio natural) são ferramentas para o desenvolvimento de conceitos associados às funções de domínio real (por exemplo, o estudo de sequências de diferenças como base para o estudo de quocientes de diferenças e, posteriormente, quocientes diferenciais).

Respaldados nas ideias dos autores previamente estudados, e compreendendo-as não como excludentes, mas complementares, nossa proposta de organização dos conteúdos da disciplina de CDI tem sido moldada pelas discussões geradas a partir das tarefas propostas, não estando "engessada" pelo que se planeja no início de cada semestre, mas seguindo certo "fio condutor". Em Trevisan e Mendes (2017) descrevemos e justificamos uma proposta de estrutura curricular "não usual" para a disciplina de CDI 1 que temos adotado em nossas aulas, que possibilita um adiamento do tratamento rigoroso de limites, privilegiando a exploração de ideias intuitivas que fomentassem a elaboração de conceitos matemáticos. 


\section{AS TAREFAS QUE COMPÕEM O AMBIENTE}

Inspirados nas ideias de Watson et al. (2013), entendemos, no âmbito do projeto em tela, que o termo tarefa descreve "o amplo espectro composto por 'coisas a fazer' pelos estudantes em sala de aula, o que inclui desde a execução de exercícios algorítmicos até a realização de investigações ou construção de modelos matemáticos" (TREVISAN; BORSSOI; ELIAS, 2015, p. 3).

Em Fonseca e Trevisan (2016), é apresentada uma caracterização de tarefa sob dois aspectos: os tipos de raciocínios requeridos em sua resolução e os níveis de demanda cognitiva. Acerca do primeiro aspecto, Lithner (2008) destaca que o "comportamento matemático" do estudante é influenciado, em grande parte, pelo ambiente de ensino e aprendizagem no qual está inserido (o tipo de aula da qual participa, o encaminhamento dado por seus professores, os livros didáticos, os exames aos quais é submetido), que implicam no desenvolvimento de esquemas de raciocínios superficiais, como raciocínio baseado na identificação de similaridades ("decoreba" ou apoiado no uso de alguma palavra-chave ou busca de similaridades com exemplos apresentados previamente) e o raciocínio baseado em experiências estabelecidas (estabelecido a partir de experiências provenientes do ambiente de ensino, na busca de similaridades com situações familiares).

Acerca do segundo aspecto, respaldados nos trabalhos das pesquisadoras norte-americanas Stein e Smith (2009), apontamos que tarefas que contemplem níveis de demanda cognitiva mais elevada (que demandam o uso de procedimento em conexão com significado e fazer matemática) são desejáveis na proposição de episódios de resolução de tarefas. Fonseca e Trevisan (2016) apresentam, como exemplo, uma tarefa envolvendo a exploração do volume máximo de uma caixa, que pode ser proposta já nas primeiras aulas de um curso de CDI, desencadeando discussões que levem a uma primeira formulação, ainda em caráter intuitivo e provisório, do conceito de derivada, mas também passível de ser "revisitada" em outros momentos do curso, à medida que outros conceitos matemáticos são formalizados.

Para Reis (2009), a proposta de ensino de CDI apresentada em livros é, ainda, predominantemente formalista e procedimental, havendo a necessidade de explorar os aspectos intuitivos dos conceitos. Exemplos de tarefas que oportunizam abordagens intuitivas são analisados também em Trevisan e Mendes (2013), Trevisan, Borssoi e Elias (2015), Couto, Trevisan e Fonseca (2016) e Mendes e Trevisan (2016), todos oriundos de experiências desenvolvidas junto a estudantes ingressantes em turmas de CDI. Enquanto Trevisan, Borssoi e Elias (2015) apresentam e discutem resultados de uma investigação realizada no movimento de elaborar, aplicar, analisar, discutir e reelaborar uma sequência de tarefas desencadeada por uma situação envolvendo a construção de uma calha, Couto, Trevisan e Fonseca (2016) propõem uma tarefa investigativa que envolve os parâmetros de uma função exponencial, utilizando um aplicativo no GeoGebra Tube. Por fim, Mendes e Trevisan (2016) propõem uma tarefa que possibilita aos estudantes vivenciarem um primeiro contato com a construção de modelos. Nela, são fornecidos os dados e as informações necessárias para formular hipóteses, deduzir e validar modelos, podendo ser caracterizada como desencadeadora do primeiro momento da modelagem.

Das experiências relatadas, em Trevisan e Mendes (2013), a partir da discussão de uma situação (Estudar a concentração de sal em um tanque no 
decorrer do tempo), destaca-se a quebra de um corriqueiro contrato didático segundo o qual o estudante responde questões apenas após a explicação do professor. O conhecimento matemático mostrou-se dinâmico e construído a partir das relações, justificativas, análise e validações estabelecidas pelos envolvidos e não como algo pronto e acabado. Os estudantes se expressaram de forma oral e escrita e justificaram seus pensamentos por meio da exploração de situações, questionamentos e conjecturas, e o professor procurou favorecer, valorizar e explorar as explicitações das perspectivas dos estudantes para que os conhecimentos fossem revelados e compartilhados, e insights ocorressem.

Verificamos que, em Trevisan, Borssoi e Elias (2015) e Couto, Trevisan e Fonseca (2016), os estudantes tiveram dificuldades para lidar com as situações quando apresentadas de uma forma mais aberta (por exemplo, Determine a configuração de uma calha que maximize sua capacidade de recolher água, ou Investigue a função e anote o que achar pertinente), uma vez que normalmente não estão habituados com tarefas de cunho investigativo, mas com aquelas que (?) envolvam a utilização de algoritmos que levam a uma única resposta (em geral, numérica). Percebemos, assim, que um desenho, que se mostra mais adequado à organização de episódios de resolução de tarefas, envolve, ao menos nos primeiros episódios desenvolvidos nas turmas, proposições mais fechadas, como foi o caso da reformulação da tarefa da calha (na qual aos estudantes foram fornecidas mais informações e menos opções para pensar no formato da calha) ou na exploração dos parâmetros da função (indicando ao estudante iniciar suas explorações por meio de alguns questionamentos preliminares).

Esse desenho, que, nos primeiros episódios, considera uma tarefa em uma formulação mais "fechada", mas que, no decorrer do curso, vai "se abrindo" (sem perder o caráter investigativo e que contemple os pressupostos já discutidos acerca de um ambiente de ensino e aprendizagem pautado em episódios de resolução de tarefas) tem se mostrado mais propício em nosso contexto real de ensino. A experiência relatada em Mendes e Trevisan (2016, p.12) apontou que o estudante,

\begin{abstract}
ao vivenciar episódios de resolução de tarefas em aulas de CDI, [...] tem a oportunidade, por meio da produção elaborada em conjunto de seus colegas, de aprender, não só no fazer, mas progressivamente no entender e no explicar suas escolhas, sendo dado a ele a oportunidade de rever os caminhos escolhidos. O professor, ao invés de ser o mentor de explicações, é o que incentiva as discussões, é o que questiona as ideias levantadas pelos alunos, e também aquele que conduz a sistematização dos conceitos subjacentes às produções realizadas pelos alunos, a partir das tarefas planejadas.
\end{abstract}

Outro elemento que destacamos, ao pensar o desenho das tarefas que compõem o ambiente, é a incorporação de recursos tecnológicos. Concordamos com Borba, Silva e Gadanidis (2015, p. 48) quando destacam a "importância de se discutir aspectos sobre o processo de elaboração de atividades matemáticas [entendidas como sinônimo de tarefas] baseadas no uso de tecnologias educacionais". Reforçam também que "é fundamental explorarmos não somente os recursos inovadores de uma tecnologia educacional, mas a forma de uso de suas potencialidades com base em uma perspectiva educacional" (BORBA; SILVA; GADANIDIS, 2015, p. 48).

Respaldados nas ideias desses autores, Trevisan, Elias e Aranda (2016) 
um livro da disciplina de CDI-1, que fazem uso de recursos computacionais, segundo a concepção de uso de tecnologia subjacente aos seus processos de resolução. Resultaram daí três agrupamentos, mostrados no Quadro 1.

Quadro 1 - Concepção de uso de tecnologia subjacente aos processos de resolução de tarefas de um livro de Cálculo.

\begin{tabular}{|c|c|c|}
\hline Concepção & Breve descrição & Exemplo \\
\hline $\begin{array}{l}\text { Tecnologia como } \\
\text { recurso para a } \\
\text { conferência de } \\
\text { respostas }\end{array}$ & $\begin{array}{l}\text { O uso do recurso computacional é sugerido, } \\
\text { ou como instrumento para verificar uma } \\
\text { resposta, ou para confirmar alguma } \\
\text { hipótese/conjectura obtida anteriormente } \\
\text { com lápis e papel. }\end{array}$ & $\begin{array}{l}\text { Esboçar o gráfico de uma } \\
\text { função e utilizar o recurso } \\
\text { computacional para conferir a } \\
\text { construção. }\end{array}$ \\
\hline $\begin{array}{l}\text { Tecnologia como } \\
\text { recurso para } \\
\text { mudar o foco das } \\
\text { tarefas }\end{array}$ & $\begin{array}{l}\text { Sugerem o uso do recurso computacional } \\
\text { para gerar um gráfico e, a partir dele, } \\
\text { estimar valores numéricos ou propriedades } \\
\text { da função investigada }\end{array}$ & $\begin{array}{l}\text { Esboçar o gráfico de uma } \\
\text { função com auxílio do recurso } \\
\text { computacional e utilizá-lo } \\
\text { para estimar a existência de } \\
\text { pontos críticos. }\end{array}$ \\
\hline $\begin{array}{l}\text { Tecnologia como } \\
\text { aliada à } \\
\text { experimentação } \\
\text { matemática }\end{array}$ & $\begin{array}{l}\text { Sugerem o estabelecimento de diversas } \\
\text { correlações visuais e coordenação entre } \\
\text { expressão gráfica e algébrica, favorecendo } \\
\text { a experimentação e visualização. }\end{array}$ & $\begin{array}{l}\text { Utilizar o recurso } \\
\text { computacional para gerar uma } \\
\text { família de gráficos de uma } \\
\text { função em função de um } \\
\text { parâmetro, e investigar o } \\
\text { papel deste na localização de } \\
\text { pontos críticos. }\end{array}$ \\
\hline
\end{tabular}

Fonte: Baseado em Trevisan, Elias e Aranda (2016).

No caso do último agrupamento, a incorporação da tecnologia envolve uma modificação nas formas de fazer matemática, atribuindo um design experimental à atividade matemática. Embora tenham escolhido para análise um livro que apresenta potencial para tarefas diferenciadas, os autores detectaram que um baixo número delas se aproxima dessa perspectiva (12 tarefas, num universo de 539 presentes no livro), o que indica a necessidade de investigar possíveis formas para sua reformulação. Em especial, apresenta-se naquele trabalho uma proposta nesse sentido (uma tarefa envolvendo transformações de funções), com vistas a potencializar os processos de formulação e refinamento de conjecturas, bem como conexões entre representações e objetos matemáticos.

Ressalta-se que as ações desenvolvidas no projeto incluem, como suporte à proposta de ambientes de ensino e aprendizagem de CDI pautados em resolução de tarefas, a criação e/ou a adaptação intencional de tarefas de livros didáticos e outros materiais curriculares com o objetivo de.

[...] serem diversificadas no seu contexto (puramente matemático ou relacionado com a realidade) e por se estruturarem de modo a apelarem à familiarização com uma dada representação inicial, pedirem explicitamente a transição entre diversas representações e requererem a escolha de uma ou mais representações para responder a questões de exploração (GAFANHOTO; CANAVARRO, 2014, p. 113).

Trevisan, Elias e Aranda (2016) apresentam um exemplo de reformulação de tarefa Trata-se de uma proposta de utilização dos recursos tecnológicos para investigar processos de transformação no gráfico de uma função, por meio de translações, reflexões, alongamentos e compreensões.

Em continuidade a esse último trabalho, esses autores analisam a proposição da tarefa reformulada em uma situação de avaliação, sem antes ter trabalhado em 
sala de aula, de forma sistemática, o conteúdo explorado na tarefa. Entre os resultados, apontaram como potencialidades que, em seu novo formato, a tarefa permitiu o resgate de tópicos da Educação Básica e, ao mesmo tempo, mostrou-se propícia para estabelecer relações com conceitos futuros, caracterizando a avaliação como oportunidade de aprendizagem. Por outro lado, os autores destacaram, na redação da resposta de alguns grupos, a presença de elementos que pareciam indicar mais a preocupação em "atingir" uma suposta resposta esperada pelo professor do que resultados de uma autêntica experimentação com tecnologias, indicando a necessidade de uma melhor negociação entre professor e estudantes sobre o que se espera na proposição de uma tarefa em um contexto de avaliação. Em especial, no que diz respeito às práticas avaliativas presentes no contexto de salas de aulas regulares, o desafio que se coloca é como "operacionalizar" ações na direção de uma ação formativa, aspecto não explorado neste texto.

Os resultados apresentados nesses trabalhos reforçam os pressupostos de Borba, Silva e Gadanidis (2015), segundo os quais uma tarefa matemática, elaborada com base na noção de experimentação com tecnologias, deve oferecer meios para (entre outros) geração de conjecturas matemáticas e realização de testes usando um grande número de exemplos; para criação e conexão entre diferentes (e múltiplos) tipos de representações de objetos matemáticos; para incentivo à combinação dos raciocínios intuitivo, indutivo ou abdutivo, que podem contribuir para o desenvolvimento do raciocínio dedutivo e para a criação de tarefas matemáticas "abertas controladas", ou seja, com direcionalidade ao seu objetivo.

Reiteremos, por fim, o papel decisivo da escolha de uma tarefa na organização de um ambiente de ensino e aprendizagem pautado em episódios de resolução de tarefas. Destacamos também que a "identificação de tarefas que parecem interessantes é um passo importante, mas é necessário perspectivar a sua utilização com os alunos em função dos propósitos matemáticos do ensino" (GAFANHOTO; CANAVARRO, 2014, p. 131). Investigações, como as que vêm sendo realizadas por estudantes de mestrado partícipes do projeto em tela, envolvem a realização de experiências que fundamentem propostas de ensino subsidiadas por sequências de tarefas.

\section{CONSIDERAÇÕES FINAIS}

Com o presente texto, que sistematiza resultados oriundos de pesquisas desenvolvidas no âmbito de um projeto mais amplo envolvendo a caracterização de um ambiente de ensino e de aprendizagem de CDI em condições reais de ensino, apresentamos uma discussão de elementos centrais desses ambientes (o contexto real de trabalho; o perfil dos estudantes; a organização dos conteúdos; as tarefas que o compõem), não com a intenção de caracterizar um ambiente "ideal", mas para trazer a atenção para algumas possibilidades.

Com relação ao contexto real de trabalho e perfil dos alunos, reconhecemos uma sala de aula tradicional, numerosa, com alunos que possuem dúvidas de suas escolhas vocacionais e esperam um professor detentor e transmissor do conhecimento, de tal modo que recebam um conhecimento pronto. Acreditamos 
resolução de tarefas pode oferecer a esses alunos a oportunidade de se reconhecerem responsáveis por sua aprendizagem, desenvolverem autonomia nas suas escolhas, criarem uma relação em que atuem em conjunto com seus colegas e o professor como construtores do conhecimento, em que o professor atue como guia nessa construção (COUTO; FONSECA; TREVISAN, 2017).

Ao falarmos da organização dos conteúdos, entendemos que, enquanto professores-pesquisadores, apesar de a disciplina ter uma ementa estabelecida, precisamos nos debruçar sobre os seus pontos centrais, repensar a ordem em que cada conceito pode ser explorado e sistematizado pelos alunos. Logo devemos assumir o CDI como uma disciplina dinâmica e historicamente elaborada por problemas da humanidade, e não estática.

Nesse ambiente de ensino e aprendizagem, as tarefas têm um papel central, pois elas favorecem aos alunos refinar concepções intuitivas, estabelecer relações entre os conceitos envolvidos, o que permitirá a alunos e professor construírem uma narrativa ao longo do semestre por meio de episódios em que dependem um do outro. $O$ desenho das tarefas ao longo do curso de CDI vai se modificando, de um desenho de tarefas mais fechadas (direcionadas) para tarefas mais abertas, uma vez que o estudante se habitua a lidar com esses episódios, reconhecendo neles a oportunidade de aprender ideias matemáticas.

Apesar de já termos evidenciado em nossas práticas e de nos fundamentarmos em experiências de outros pesquisadores que constataram resultados promissores nesse tipo de abordagem e nos aspectos que a circunscrevem, continuamos debruçados sobre algumas questões que nos fazem seguir em busca de caracterizar melhor o ambiente descrito ao longo do texto. Algumas das questões que norteiam essa busca são estas: Que características devem ter as situações envolvidas nas tarefas? Como criar condições para que os alunos possam se envolver em atividades colaborativas de resolução de problemas e reflexão com base nos materiais curriculares disponíveis? Como planejar tarefas que propiciem a elaboração do pensamento matemático avançado? Como organizar as práticas avaliativas? Qual o papel das TIC nesse processo? 


\title{
Teaching and learning environments of Differential and Integral Calculus organized from task resolution episodes: a proposal
}

\begin{abstract}
In general, Differential and Integral Calculus (CDI) courses are conducted through the script: presentations of definitions, examples and illustrations of concepts present in the syllabus of the subject, resolution of standard exercises and written test. On the other hand, based on research in the area of teaching of CDI and Realistic Mathematical Education (RME) we defend the organization of teaching and learning environments based on episodes of task resolutions. The objective of this work is to present a possible characterization of this environment, built in light of RME's assumptions and research and reflection on our practice. In this characterization, the following stand out: real work context, student profile, content organization and tasks that make up the environment. This text is the result of a qualitative research, which presents an analysis based on studies of the theoretical basis as well as data already collected in the classes in which the proposal has this implemented.
\end{abstract}

KEYWORDS: Teaching Mathematics. Differential and Integral Calculus teaching, Teaching and learning environment. Task resolution episodes. 


\section{AGRADECIMENTOS}

Os autores agradecem ao CNPq (Processo 457765/2014-3) pelo auxílio à realização do projeto do qual resulta este artigo.

\section{REFERÊNCIAS}

ALVARENGA, K.B.; SAMPAIO, M.M.de. Obstáculos referentes às relações de representação aritmética e algébrica de grandezas. In: FONSECA, L. (Org.). Didática do Cálculo: epistemologia, ensino e aprendizagem. 1. ed. São Paulo: Editora Livraria da Física, 2016, p. 131-144.

ANDRADE, S. N.; DIAS, M. A.; CAMPOS, T. M. M. Pesquisas sobre a transição Ensino Médio e Ensino Superior. In: Comitê Internacional de Matemática Educativa e Colégio Mexicano de Matemática Educativa. (Org.). Acta Latinoamericana de Matemática Educativa. 27ed. Buenos Aires: ALME 27, 2014, v. 27, p. $171-180$.

ARTIGUE, M. Engenharia Didática. In: BRUN, J. Didática das Matemáticas. Tradução de: Maria José Figueiredo. Lisboa: Instituto Piaget, 1995, p. 193-217.

BORBA. M.C.; SILVA, R.S.R; GADANIDIS, G. Fases das tecnologias digitais em Educação Matemática, Sala de aula e internet em movimento. Belo Horizonte: Autêntica, 2015. (Coleção Tendências em Educação Matemática).

BORGES, P. A. P.; MORETTI, M. T. A relação com o saber matemático de alunos ingressantes na universidade. Educação Matemática Pesquisa (On-line), v. 18, p. 485-510, 2016.

BORSSOI, A. H.; SILVA, K. A. P.; FERRUZZI, E. C. Tarefas desencadeadas em aulas com modelagem matemática. In: Encontro Nacional de Educação Matemática, 2016, São Paulo. Anais... ENEM, 12. São Paulo: Sociedade Brasileira de Educação Matemática, 2016. p. 1-12.

COUTO, A. F.; FONSECA, M. O. S.; TREVISAN, A. L. Aulas de Cálculo Diferencial e Integral organizadas a partir de episódios de resolução de tarefas: um convite à insubordinação criativa. Revista de Ensino de Ciências e Matemática, v. 4, p. 5061, 2017.

COUTO, A. F.; TREVISAN, A. L.; FONSECA, M. O. S. Análise de uma tarefa investigativa proposta a estudantes de Cálculo por meio de questões do tipo 'aberto-controladas'. In: III Simpósio Nacional de Ensino e aprendizagem, 2016, Londrina. Anais... SEA, 3. Londrina: Editora da UTFPR, 2016. v.1. p. 1-9. 
CUEVAS, C. A.; MEJÍA, H. R. Un acercamiento alternativo al cálculo diferencial. In: LEZAMA, J.; SÁNCHEZ, M.; MOLINA, J. G. (Eds.), Acta Latino Americana de Matemática Educativa. México DF, México: Comité Latino Americano de Matemática Educativa, 2005, p. 741-747.

DOORMAN, M.; MAANEN, J. V. A historical perspective on teaching and learning Calculus. Australian Senior Mathematics Journal, v.22, n.2, p.4-14, 2008.

FONSECA, M. O. S.; TREVISAN, A. L. Caracterização e encaminhamento de tarefas matemáticas em aulas de Cálculo Diferencial e Integral. In: XII Encontro Nacional de Educação Matemática, 2016, São Paulo. Anais... ENEM, 12. São Paulo: SBEM, 2016, p. 1-12.

FREUDENTHAL, H. Mathematics as an Educational Task. Dordrecht: Reidel Publishing Company, 1973.

Revisiting Mathematics Education. Netherlands: Kluwer Academic Publishers, 1991.

GRAVEMEIJER, K.P.E.; COBB, P. Design research from a learning design perspective. In: VAN DEN AKKER, J; GRAVEMEIJER, K. P. E.; MCKENNEY, S.; NIEVEEN, N. (Eds.), Educational design research. London: Routledge, 2006, p. 1751.

GAFANHOTO, A. P.; CANAVARRO, A. P. A adaptação das tarefas matemáticas: como promover o uso de múltiplas representações. In PONTE, J. P. (Org.). Práticas profissionais dos professores de Matemática. Lisboa: Instituto de Educação da Universidade de Lisboa, 2014, p.113-132.

LITHNER. J. A research framework for creative and imitative reasoning. Educational Studies in Mathematics, v.67, n.3, p. 255-276, 2008.

MENDES, M. T.; TREVISAN, A. L. Modelagem matemática como componente do ambiente educacional para aulas de CDI: relato de uma experiência. In: VII Encontro Paranaense de Modelagem na Educação Matemática, 2016, Londrina. Anais... EPMEM, 7. Londrina: UEL/UTFPR, 2016. v. 1. p. 722-735.

MOREIRA, A. F. Ambientes de Aprendizagem no Ensino de Ciência e Tecnologia. Belo Horizonte: CEFET-MG, 2007.

PALHA, S. A. G. Shift-Problem Lessons: Fostering Mathematical Reasoning in Regular Classrooms. Research Institute of Child Development and Education, University of Amsterdam, The Netherlands, 2013. 
RAMOS, N. S.; FONSECA, M. O. S.; TREVISAN, A. L. Ambiente de aprendizagem de Cálculo Diferencial e Integral pautado em episódios de resolução de tarefas. In: V Simpósio Nacional de Ensino de Ciência e Tecnologia, 2016, Ponta Grossa. Anais... SINECT, 5. Ponta Grossa: Editora da UTFPR, 2016. v. 1. p. 1-11.

RASMUSSEN, C; MARRONGELE, K; BORBA, M. C. Research on calculus: what do we know and where do we need to go? ZDM, v. 46, p. 507-515, 2014.

REIS, F. S. Rigor e Intuição no Ensino de Cálculo e Análise. In: Lilian Nasser; Maria Clara Rezende Frota. (Org.). Educação Matemática no Ensino Superior: Pesquisas e Debates. 1.ed. Recife - PE: Sociedade Brasileira de Educação Matemática, 2009, v. 1, p. 81-97.

REZENDE, W. M. O Ensino de Cálculo: Dificuldades de Natureza Epistemológica. In: II Seminário Internacional de Pesquisa em Educação Matemática, 2003, Santos. Anais... Seminário Internacional de Pesquisa em Educação Matemática, II, Santos: SBEM, 2003, p. 1-20.

STEIN, M.H.; SMITH, M.S. Tarefas matemáticas como quadro para reflexão. Educação e Matemática, n.105, 2009, p. 22-28.

STINGLER, J.; HIEBERT, J. Improving mathematics teaching. Educational Leadership, v.5, n.61, p. 12-16, 2004.

TREVISAN, A. L.; MENDES, M. T. Possibilidades para matematizar em aulas de Cálculo. Revista Brasileira de Ensino de Ciência e Tecnologia, v. 6, p. 129-138, 2013.

TREVISAN, A. L.; BORSSOI, A.H.; ELIAS, H. R. Delineamento de uma Sequência de Tarefas para um Ambiente Educacional de Cálculo. VI Seminário Internacional de Pesquisa em Educação Matemática, Pirinópolis/GO, 2015. Anais... Seminário Internacional de Pesquisa em Educação Matemática, 6, Brasília: SBEM, 2015, p. 1-12.

TREVISAN, A. L.; ELIAS, H. R.; ARANDA, V. Um estudo de tarefas de Cálculo Diferencial e Integral com auxílio de recursos computacionais. In: VII Congresso Mundial de estilos de aprendizagem, 2016, Bragança. Anais... CMEA, 7. Bragança - Portugal: Biblioteca Digital do IPB, 2016, p. 1908-1916.

TREVISAN, A. L.; ELIAS, H. R. Tarefas matemáticas para avaliação em aulas de Cálculo Diferencial e Integral. In: VIII Congresso Ibero-americano de Educação Matemática, 2017, Madrid. Anais... CIBEM, 8. Madrid-Espanha: 2017, p. 1-8. 
TREVISAN, A. L.; MENDES, M. T. Integral antes de derivada? Derivada antes de integral? Limite, no final? Uma proposta para organizar um curso de Cálculo Integral. Educação Matemática Pesquisa, v. 19, p. 353-373, 2017.

VALLEJO, C. A. C.; PLUVINAGE, F. Cálculo y Tecnologia. El Cálculo y su Ensenãnza, v. 1, p. 01-15, 2009.

VALLEJO, C. A. C.; MARTÍNEZ, M.; PLUVINAGE, F. Promoviendo el pensamiento funcional en la ensenãnza de Cálculo. Annales de Didactique et de Sciences Cognitives, v. 17, p. 137-168, 2012.

WATSON, A; OHTANI, M; AINLEY, J.; FRANT, J. B.; DOORMAN, M.; KIERAN, C.; LEUNG, A.; MARGOLINAS, C.; SULLIVAN, P.; THOMPSON, D.; YANG, Y. Task Design in Mathematics Education. MARGOLINAS, C et al. (Eds.). Proceedings... ICMI, 22. Oxford: ICMI, 2013, p. 9 -16.

WEIGAND, H. G. A discrete approach to the concept of derivative. ZDM, n. 46, p. 603-619, 2014.
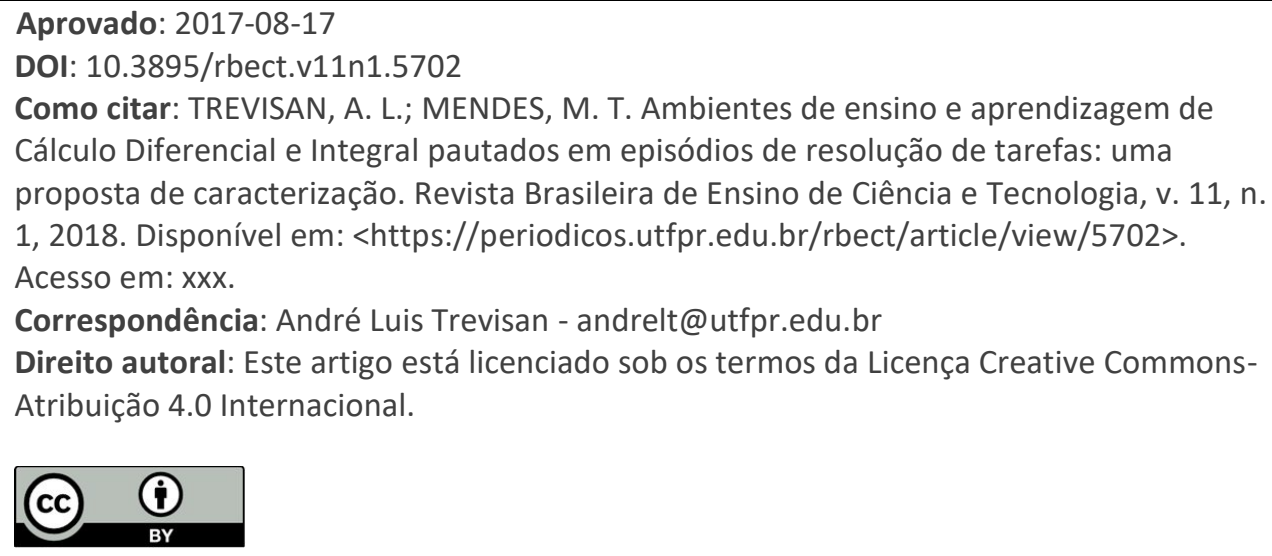